\title{
A rapid and sensitive method for measuring the conditioned emotional response: Off-the-baseline delay and trace conditioning
}

\author{
W. J. JACOBS \\ University of Lethbridge, Lethbridge, Alberta, Canada \\ and \\ D. KENNEDY and M. BUTTRICK
University of British Columbia, Vancouver, British Columbia, Canada
}

We outline a rapid method of detecting excitatory conditioning in rats, using a conditioned emotional response procedure. The procedure requires a total of only 2 experimental days to complete deprivation, conditioning, baseline training, and testing. Using an off-the-baseline procedure, we demonstrate that the method is sensitive to both delay and trace conditioning.

We outline a procedure that is both rapid and convenient to use, is sensitive to Pavlovian phenomena, and is, compared with other conditioning procedures, relatively easy on the experimental subjects.

\section{EXPERIMENT 1}

The first experiment demonstrated that excitatory fear conditioning may be detected in a fully controlled experiment that requires only 2 experimental days: a day of conditioning and a day of testing. The time required to complete the five daily experimental treatments was less than $4 \mathrm{~h}$ each day.

Method
Subjects
Fifty experimentally naive Long-Evans rats, weighing $100-150 \mathrm{~g}$ at
the beginning of the experiment, were used. The rats were locally bred
and were maintained on a reversed $12 / 12-\mathrm{h}$ day/night cycle. They were
individually housed and were given free access to food and water be-
fore the beginning of the experiment. The training and conditioning ses-
sions were conducted during the night portion of the day/night cycle.

\section{Apparatus}

Ten Perspex chambers $(25 \times 30 \times 18 \mathrm{~cm})$ similar to that described by Swartzwelder et al. (1980) were used. Each chamber had a 1-cmdiameter hole centered in the front wall $4 \mathrm{~cm}$ above the floor. Two additional 1-cm-diameter holes were centered on either side of this hole at the same height above the floor. Two stainless steel rods $(7 \times 0.5 \mathrm{~cm})$ were mounted outside the chamber on each side of the three openings, $1 \mathrm{~cm}$ beneath them. A Perspex block $(6 \times 2 \times 3 \mathrm{~cm})$, which could be moved either toward or away from the chamber and locked in place, was attached to the rods beneath the center hole. A licking tube consisting of three 19-ga stainless steel tubes was mounted in the Perspex block. The three-tube configuration was mounted so that the tip entered

This work was supported by NSERC University Research Fellowship U0262 awarded to W. J. J. Address reprint requests to W. J. Jacobs, Department of Psychology, 4401 University Drive, University of Lethbridge, Lethbridge, AB T1K 3M4, Canada. the center of the middle hole at a $30^{\circ}$ angle. Thus, the rat could contact the tube by extending its tongue into the hole.

The licking tube was attached to a solenoid valve mounted outside the $44 \times 32 \times 30 \mathrm{~cm}$ sound-attenuating chamber via plastic tubing. The solenoid valve was also attached to a reservoir (hypodermic syringe bodies) via the tubing. The reservoir contained a $0.1 \%$ saccharin solution. A controlled amount of the saccharin solution could be delivered to the licking tube by timed operation of the solenoid valve.

A 28-V houselight was centered on the front wall of the chamber, $10.7 \mathrm{~cm}$ from the grid floor. A speaker was center mounted on the ceiling of the chamber. The floor consisted of stainless steel grids, $3 \mathrm{~mm}$ in diameter, mounted $0.6 \mathrm{~cm}$ center to center. The grid floor and the licking tube were attached to a lickometer/shock circuit built in-house. The lickometers were designed in such a way that the licking tube became electrically isolated when scrambled electric shock was delivered to the grid floor.

The experimental conditions and data collection were controlled through a computer located in an adjacent room.

\section{Procedure}

Each rat was given $48 \mathrm{~h}$ of continuous exposure to a $0.1 \%$ saccharin solution 1 week before the beginning of the experiment. This exposure eliminated neophobia to saccharin.

Conditioning day. The rats were removed from their home cages and confined in the experimental chamber for a 20 -min conditioning session. Water deprivation began for each rat at this time. On this experimental day, the licking tube was not present in the chamber. Each rat received one of the following experimental treatments.

The 10 rats in the CS-UCS group received six 30 -sec presentations of the conditional stimulus (CS; a 0.32-sec on, 0.12-sec off flashing of the houselight), followed immediately by the presentation of the unconditional stimulus (UCS; a 0.75-sec, 1.0-mA scrambled electric shock). These conditioning trials were presented on a variable-time 190-sec (VT190) schedule. The minimum intertrial interval was $60 \mathrm{sec}$.

The 10 rats in the CS-alone group received six presentations of the 30-sec flashing houselight on the same schedule as that described for the rats in the CS-UCS group. No programmed experimental events preceded or followed these presentations.

The 10 rats in the UCS-alone group received six presentations of the UCS on the same schedule as that received by the rats in the CS-alone group.

For the 10 rats in the CS/UCS-random group, the flashing houselight and electric shock were presented independently of one another. Six presentations of the CS and six presentations of the UCS were controlled 
by independent VT-190 schedules with a minimum intertrial interval of $50 \mathrm{sec}$.

The 10 rats in the placement group received no scheduled presentations of the CS or UCS. They were simply placed in the experimental chamber on this day.

All rats were returned to their home cages immediately following the conditioning session.

Test day. Twenty-four hours after water deprivation, the rats were placed in the experimental chamber with the licking tube present and were trained to lick for $0.15 \mathrm{sec}$ (approximately $0.01 \mathrm{cc}$ ) access to a $0.1 \%$ saccharin solution. Licking produced access to the solution on a variable-ratio 3 (VR-3) schedule of reinforcement for the first 20 presentations, a VR-5 schedule for the next 20, and a VR-10 schedule for the remainder of the experimental session.

After each rat had achieved the VR-10 schedule, testing of the behavioral effects of the CS began. The 30 -sec CS was presented six times on a variable-interval $95-\mathrm{sec}$ schedule. The rats were required to perform a minimum of five licks during the $30-\mathrm{sec}$ interval that immediately preceded presentation of the CS. If fewer than five licks occurred during that interval, then the interval was reset. This continued until the response criterion was met. The number of licks that occurred during the 30 -sec intervals immediately before and during presentations of the CS were recorded.

Statistical analysis. Supression ratios were calculated using the expression $A /(A+B)$, where $A$ is the number of responses in the presence of the CS and $B$ is the number of responses in the 30 -sec period that occurred immediately before presentation of the CS. The ratio yields a value of 0.50 if the rate of licking does not change in the presence of the CS and a value below 0.50 if the rate of licking decreases in its presence. For statistical purposes, the number of responses obtained during the six 30-sec periods that preceded presentations of the CS and the number of responses obtained during the six presentations of the CS yielded a single suppression ratio.

Statistical analyses were carried out using Rodger's (1974, 1975a, 1975b) method (see also Baker, Mercier, Gabel, \& Baker, 1981; Goodkin, 1976; Jacobs \& LoLordo, 1980; Urcuioli \& Honig, 1980). The Type I error rate was set at 0.05 for each statistical decision.

\section{Results}

All rats responded at stable rates during the 30 -sec periods that preceded presentations of the CS. The rates

\section{DELAY CONDITIONING}

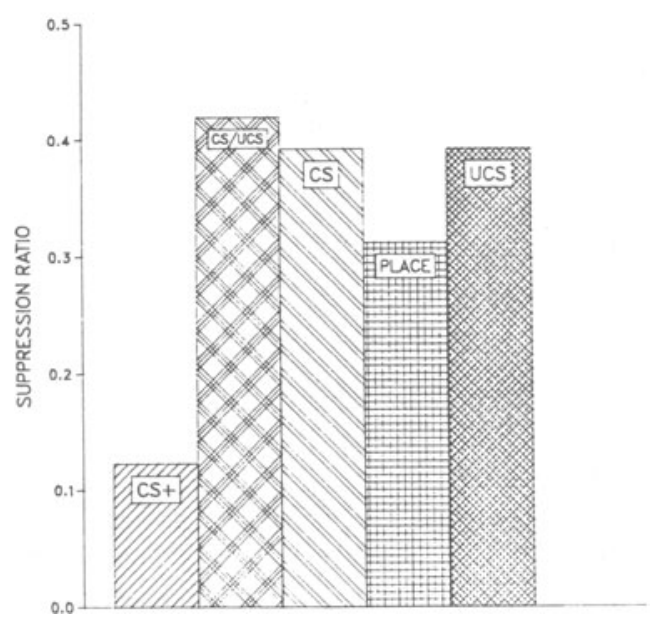

Figure 1. Mean suppression ratios obtained for the CS-UCS group (CS +), the CS/UCS-random group (CS/UCS), the CS-alone group (CS), the placement group (PLACE), and the UCS-alone group (UCS). ranged from 2.8 to 4.0 licks per second. An analysis of variance did not reveal any differences in the mean rates of responding among the groups.

The mean suppression ratios obtained on the test day are presented in Figure 1. This figure shows that suppression of the ongoing licking response resulted from the presentation of the CS that had been systematically related to electric shock. The rats that had no experience with a temporally related CS and UCS showed little suppression in the presence of the flashing light.

An analysis of variance detected significant differences among the group means $[F(4,45)=15.83]$. Post hoc analysis revealed no significant differences among the mean suppression ratios obtained for the CS-alone, CS/UCSrandom, and placement groups. The mean ratios of these groups taken together differed significantly from the mean of the CS-UCS group $(F=15.40)$. This set of decisions implies the following ordering of the population means:

$$
\begin{aligned}
\text { CS-alone } & =\mathrm{UCS} \text {-alone }=\text { placement } \\
& =\mathrm{CS} / \mathrm{UCS} \text { random }>\text { CS-UCS }
\end{aligned}
$$

This order of means is what would be expected in an experiment designed to examine the associative basis of the conditioned emotional response.

\section{EXPERIMENT 2}

The purpose of Experiment 2 was to demonstrate that the conditioned suppression observed in Experiment 1 follows another well-known Pavlovian rule. In this case, we demonstrated the effect of varying the temporal interval between the termination of the CS and the presentation of the UCS.

\section{Subjects}

Forty-five experimentally naive Long-Evans rats, weighing 100-150 g at the beginning of the experiment, were used. The rats were adapted, housed, maintained, and preexposed to saccharin as in Experiment 1.

\section{Apparatus}

The apparatus used in Experiment 1 was used in Experiment 2.

\section{Procedure}

Conditioning day. The 9 rats in the delay group received six 30 -sec presentations of the flashing houselight (the CS), immediately followed by a $0.75-\mathrm{sec}, 1.0-\mathrm{mA}$ scrambled electric shock (the UCS) during the first experimental session. The procedure exactly paralleled that used for the CS-UCS group of Experiment 1.

For the 9 rats in the 1-sec trace group, the termination of the CS was followed $1 \mathrm{sec}$ later by a presentation of the UCS. The six trials were administered as for the delay group.

For the 9 rats in the 5-sec trace group, the termination of the CS was followed $5 \mathrm{sec}$ later by a presentation of the UCS. The six trials were administered as for the delay group.

For the 9 rats in the 10-sec trace group, the termination of the CS was followed $10 \mathrm{sec}$ later by a presentation of the UCS. The six trials were administered as for the delay group.

The 9 rats in the CS/UCS-random group were treated just like those in the CS/UCS-random group of Experiment 1.

Test day. Baseline training and testing were carried out $24 \mathrm{~h}$ following conditioning, as described in Experiment 1. 


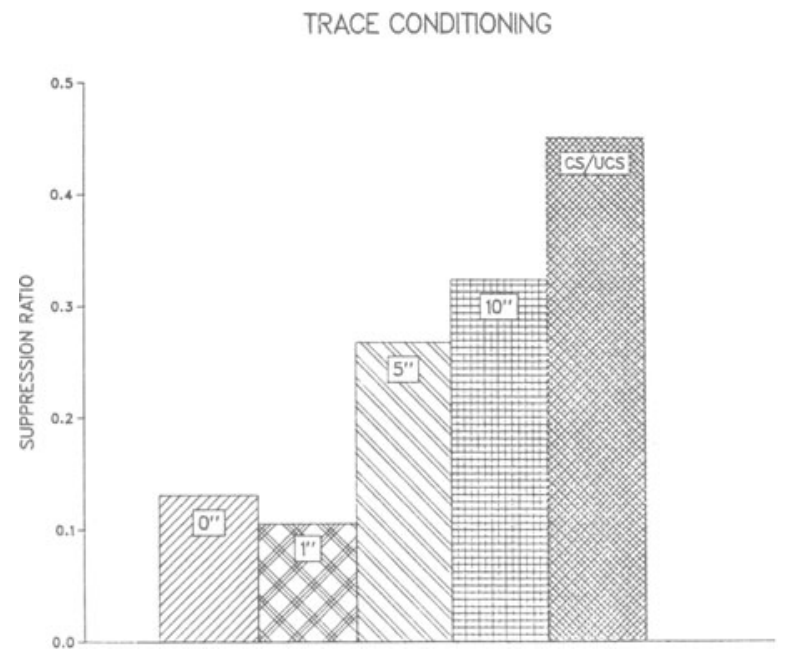

Figure 2. Mean suppression ratios obtained for the delay group $\left(0^{\prime \prime}\right), 1$-sec trace group (1"), 5-sec trace group $\left(5^{\prime \prime}\right), 10$-sec trace group $\left(10^{\prime \prime}\right)$, and CS/UCS-random group (CS/UCS).

\section{Results}

All rats responded at stable rates during the 30 -sec periods that preceded presentations of the CS. The rates ranged from 2.55 to 3.6 licks per second. An analysis of variance failed to reveal any differences in the mean rates of responding among the groups.

An analysis of variance conducted on the mean suppression ratio obtained for each group (see Figure 2) revealed significant differences among the groups $[F(4,40)=$ 12.98].

A post hoc analysis revealed differences between mean suppression ratios of the delay and 1-sec trace groups. These ratios taken together differed significantly from the mean suppression ratio obtained from the 5-sec trace group $(F=2.49)$. The mean suppression ratios of these three groups differed significantly from the mean ratio of the 10-sec trace group $(F=2.89)$. Finally, the means of these four groups taken together differed significantly from the ratio obtained from the CS/UCS-random group $(F=7.17)$. This set of decisions implies the following order of population means:

CS/UCS-random $>10$-sec trace

$$
>5 \text {-sec trace }>1-\sec \text { trace }=\text { delay }
$$

This order of the means is what would be expected when the interval between presentations of the CS and the UCS increases from 0 to $10 \mathrm{sec}$.

\section{GENERAL DISCUSSION}

\begin{abstract}
These results show that conditioned emotional responding is produced, and is easily detected, within the experimental paradigm that we have described. The results obtained from the placement group indicate that the response criterion used here does not produce artifactual response suppression during presentation of the CS. The results obtained from the CS-alone, UCS-alone, and the CS/UCS-random groups further support this assertion. These results, taken with the results obtained from the delay, 1-sec trace, 5-sec trace, and 10-sec trace groups, indicate that the suppression obtained by delay and trace procedures are dependent upon associations formed between the CS and the UCS. The results of the present experiments indicate that it is possible to complete an excitatory conditioning experiment (deprivation, conditioning, baseline training, and testing) within 2 experimental days. The use of such a procedure saves the experimenter time and effort. Perhaps more importantly, the procedure protects the experimental subjects from unnecessary longterm food or water deprivation.
\end{abstract}

\section{REFERENCES}

Baker, A. G., Mercier, P., Gabel, J., \& Baker, P. A. (1981). Contextual conditioning and the US preexposure effect in conditioned fear. Journal of Experimental Psychology: Animal Behavior Processes, 7, 109-128.

GoodKIN, F. (1976). Rats learn the relationship between responding and environmental events: An expansion of the learned helplessness hypothesis. Learning \& Motivation, 7, 282-293.

JACOBS, W. J., \& LoLoRdo, V. M. (1980). Constraints on Pavlovian aversive conditioning: Implications for avoidance learning in the rat. Learning \& Motivation, 11, 427-455.

RoDGER, R. S. (1974). Multiple contrasts, factors, error rate, and power. British Journal of Mathematical \& Statistical Psychology, 27, 127-198.

RoDGER, R. S. (1975a). The number of non-zero, post-hoc contrasts from ANOVA and error-rate. British Journal of Mathematical \& Statistical Psychology, 28, 71-78.

RoDGER, R. S. (1975b). Setting rejection rate for contrasts selected posthoc when some nulls are false. British Journal of Mathematical \& Statistical Psychology, 28, 213-232.

Swartzwelder, H. S., Taylor, M. B., Peele, D. B., Mastropaolo, J. P., Slotnic, B. M., \& Reily, A. L. (1980). The operant assessment of taste discrimination. Behavioral \& Neural Biology, 30, 345-349.

Urcuioli, P. J., \& HoniG, W. K. (1980). Control of choice in conditional discriminations by sample-specific behaviors. Journal of $E x$ perimental Psychology: Animal Behavior Processes, 6, 251-277.

(Manuscript received for publication July 6, 1987.) 